\title{
Short communication: Arginase inhibition reduces the synthesis of casein in bovine mammary epithelial cells
}

\author{
M. Z. Wang, ${ }^{* 1,2}$ L. Y. Ding, ${ }^{* 1}$ C. Wang, † L. M. Chen, ${ }^{*}$ J. J. Loor, $\ddagger$ and H. R. Wang ${ }^{* 2}$ \\ ${ }^{*}$ College of Animal Science and Technology, Yangzhou University, Yangzhou 225009, China \\ †School of Clinical Medicine, Jiangsu University, Zhenjiang 212013, Jiangsu, China \\ ‡Department of Animal Sciences and Division of Nutritional Sciences, University of Illinois, Urbana 61801
}

\section{ABSTRACT}

The main purpose of this work was to determine the effect of arginase inhibition via $N^{\omega}$-hydroxy-norL-arginine (nor-NOHA) on casein synthesis in bovine mammary epithelial cells (BMEC). Passage 2 BMEC isolated from dairy cows were seeded to 6-well plates and randomly divided into 4 treatments: (1) control [Dulbecco's modified Eagle medium:Nutrient Mixture F-12 medium (DMEM/F12)]; (2) nor-NOHA (DMEM/ $\mathrm{F} 12+1 \mathrm{mmol} / \mathrm{L}$ nor-NOHA); (3) nor-NOHA + arginine $(\mathrm{DMEM} / \mathrm{F} 12+1 \mathrm{mmol} / \mathrm{L}$ nor-NOHA $+3.2 \mathrm{mmol} / \mathrm{L}$ Arg); and (4) nor-NOHA + ornithine (DMEM/F12+ $1 \mathrm{mmol} / \mathrm{L}$ nor-NOHA $+1 \mathrm{mmol} / \mathrm{L}$ Orn). Then, we determined the activity of enzymes related to Arg metabolism and casein synthesis in BMEC and the proliferation of cells. The addition of nor-NOHA reduced the activity of arginase and ornithine decarboxylase but had no effect on the activity of nitric oxide synthase, and these responses were the same at the gene expression level. In addition, supplementation of nor-NOHA in BMEC reduced cellular proliferation and casein synthesis. Addition of Arg to nor-NOHA resulted in cellular proliferation and casein synthesis similar to that of nor-NOHA alone. In contrast, addition of Orn to the medium with nor-NOHA increased the synthesis of casein and cellular proliferation compared with Nor-NOHA. In conclusion, suppression of the Arg-arginase-Orn pathway reduced casein synthesis and cellular proliferation, which indicated that this pathway is an important regulator of the synthesis of casein in BMEC.

Key words: arginine, ornithine, $N^{\omega}$-hydroxy-nor-Larginine (nor-NOHA), milk casein, mammary epithelial cell

\footnotetext{
Received August 4, 2016.

Accepted January 7, 2017.

${ }^{1}$ These authors contributed equally to this work.

${ }^{2}$ Corresponding authors: hongrongwang@sina.com mengzhiwangyz@126.com
}

\section{Short Communication}

As a functional amino acid, Arg plays multiple roles in the body, including metabolism, immune function, and hormone secretion. Studies have indicated that Arg might also have an important role in regulating casein synthesis (Mabjeesh et al., 2002; Doepel and Lapierre, 2011). Our recent reports (Chen et al., 2013; Wu et al., 2016) confirmed that Arg increased casein protein synthesis in bovine mammary epithelial cell (BMEC) and clarified that Arg plays an important role in the transcriptional regulation of casein genes and mammalian target of rapamycin (mTOR)-related genes, which may contribute to casein protein synthesis (Wang et al., 2014).

There are 3 main routes of Arg metabolism (Li et al., 2001) in the body, and the transformation of Arg to nitric oxide (NO; $\mathbf{A r g}-\mathbf{N O}$ ) and ornithine (Orn; Arg-Orn) is the main pathway in mammary tissue (O'Quinn et al., 2002). The metabolic end products of Arg-Orn and Arg-NO are polyamines (putrescine, spermidine, and spermine) and NO, respectively (Wu et al., 2009). Some studies have reported that putrescine had positive effects on the proliferation of cells (Chen et al., 2015). The addition of putrescine in growth medium promoted the synthesis of protein in porcine trophectoderm cells (Kong et al., 2014). Furthermore, spermidine has also been reported to be associated with milk protein synthesis in mammary gland (Oka and Perry, 1974b). Arginase is regarded as the first ratelimiting enzyme in the Arg-Orn-polyamine pathway (Wu et al., 2000).

$N^{\omega}$-Hydroxy-L-arginine (NOHA) is a natural and powerful inhibitor of arginase. It competes with Arg for binding to arginase and inhibits its activity (Iniesta et al., 2001). Similarly, $N^{\omega}$-hydroxy-nor-L-arginine (norNOHA) is a new type of inhibitor that is 40 times more effective than NOHA and has no effects on the activity of nitric oxide synthase (NOS; Custot et al., 1997).

Taking into consideration the previous work described above, we hypothesized that Arg might partly 
regulate milk casein synthesis by altering arginase activity. Thus, the focus of the present study was on the effects of arginase inhibition through nor-NOHA on casein synthesis in BMEC.

All animal procedures were approved by the Yangzhou University Animal Care and Use Committee of Jiangsu Province, China. Three multiparous healthy lactating Chinese Holstein cows at similar lactation stage $(\mathrm{DIM}=100 \pm 5)$ were obtained from the Experimental Farm of Yangzhou University. Mammary gland tissue samples were harvested using a published biopsy method (Bionaz et al., 2012). Approximately 5 g of mammary tissue was added to Dulbecco's modified Eagle medium:Nutrient Mixture F-12 medium (DMEM/F12; 11330032, Invitrogen, Carlsbad, CA) containing penicillin and streptomycin $(500 \mathrm{IU} / \mathrm{mL})$. The tissue was washed with PBS supplemented with $100 \mathrm{IU} / \mathrm{mL}$ penicillin/streptomycin (P0389/S6501, Sigma, St Louis, MO), and BMEC were isolated using a sequential 2-step enzyme digestion method (Wang et al., 2014). Briefly, the tissues was sliced to $1-\mathrm{mm}^{3}$ pieces and digested with $0.5 \%$ collagenase II for $3 \mathrm{~h}$ at $38^{\circ} \mathrm{C}$. The mixture was filtered with a $74-\mu \mathrm{m}$ strainer and centrifuged for $5 \mathrm{~min}$ at $150 \times \mathrm{g}$. Mixed cells were washed with $100 \mathrm{IU} / \mathrm{mL}$ penicillin/streptomycin-supplemented PBS and inoculated in a $25-\mathrm{cm}^{2}$ culture flask for $2 \mathrm{~h}$ with growth medium: DMEM/F12 with $10 \%$ fetal bovine serum (16000-044, Gibco, Carlsbad, CA), 500 ng/ $\mathrm{mL}$ hydrocortisone (S0135, Sigma), $1 \mu \mathrm{g} / \mathrm{L}$ prolactin (L6520, Sigma), $10 \mathrm{ng} / \mathrm{mL}$ epidermal growth factor (AF-100-15, Peprotech, Rocky Hill, NJ), and $100 \mathrm{IU} /$ $\mathrm{mL}$ penicillin/streptomycin. Subsequently, the growth medium containing cells was transferred into another flask and cultured at $38^{\circ} \mathrm{C}$ with $5 \% \mathrm{CO}_{2}$ for $48 \mathrm{~h}$.

The cells were then digested with trypsin (a 3-min digestion followed by a 5 -min digestion) to purify the epithelial cells. Cells were examined with an inverted microscope to ensure fibrocytes were cleared out. Immunofluorescence of cytokeratin 18 (CK-18) and gene expression of casein were detected to confirm that the isolated cells were purified BMEC. For CK-18 immunostaining, the isolated cells were inoculated in culture dishes and cultured for $24 \mathrm{~h}$ at $38^{\circ} \mathrm{C}$. The BMEC were then treated with a cold mixture of acetone and formaldehyde (1:1) for $30 \mathrm{~s}$ after washing with cooled PBS. The supernatant liquid was discarded and BMEC were washed with PBS again. Subsequently, cells were treated with formaldehyde solution containing $3 \% \mathrm{H}_{2} \mathrm{O}_{2}$ for $10 \mathrm{~min}$ and washed with PBS for 3 times for $5 \mathrm{~min}$ each time. Cells were then blocked with fetal bovine serum for $1 \mathrm{~h}$ at room temperature, followed by staining with primary antibody for $1 \mathrm{~h}$ and $1 \mathrm{~mL}$ of fluorescein isothiocyanate-labeled sheep anti-mouse $\operatorname{IgG}$ (1:64) for $40 \mathrm{~min}$ in a dark box at room temperature. The supernatant was discarded and cells were washed with PBS 3 times before visualization with a fluorescence microscope.

Passage 2 (P2) mammary epithelial cells were inoculated into 6 -well plates at a density of $5 \times 10^{4}$ and cultured in growth medium for $24 \mathrm{~h}$. The medium was changed to serum-free medium and cultured for $16 \mathrm{~h}$. Cells were then divided into 4 groups and the medium was replaced with different media as followed: (1) DMEM/F12 medium (control); (2) DMEM/F12 + $1 \mathrm{mmol} / \mathrm{L}$ nor-NOHA (Nor-NOHA); (3) DMEM/ $\mathrm{F} 12+1 \mathrm{mmol} / \mathrm{L}$ nor-NOHA $+3.2 \mathrm{mmol} / \mathrm{L}$ Arg (NorNOHA+Arg); or (4) DMEM/F12 + $1 \mathrm{mmol} / \mathrm{L}$ nor$\mathrm{NOHA}+1 \mathrm{mmol} / \mathrm{L}$ Orn (Nor-NOHA+Orn), and cells were incubated for $24 \mathrm{~h}$. Treatments were run in triplicate, and an appropriate blank (medium without cell incubation) was included.

The epithelial cells were inoculated into 96-well plates at a density of $1 \times 10^{5}$ and cultured with growth medium for $24 \mathrm{~h}$. Then, the growth medium was replaced with serum-free medium and cultured for $16 \mathrm{~h}$ before cells were divided into the 4 different treatments. Each treatment had 6 replicates. The proliferation of cells at 24,48 , and $72 \mathrm{~h}$ was evaluated with the 3(4,5-dimethylthiazol-2-yl)-2,5-diphenyl tetrazolium bromide (MTT, M6494, Invitrogen) as follows. First, the medium was removed and replaced with $100 \mu \mathrm{L}$ of fresh growth medium. A total of $10 \mu \mathrm{L}$ of $12 \mathrm{mM}$ MTT solution was then added, and the mixture was incubated at $38^{\circ} \mathrm{C}$ for $4 \mathrm{~h}$ in a humidified chamber. Subsequently, $50 \mu \mathrm{L}$ of dimethyl sulfoxide was added to each well and cultured at $38^{\circ} \mathrm{C}$ for $10 \mathrm{~min}$. Absorbance was read at $570 \mathrm{~nm}$.

The BMEC were digested with $0.25 \%$ trypsin and $0.1 \%$ EDTA-2Na at $38^{\circ} \mathrm{C}$ for 5 min after culturing with different media for $24 \mathrm{~h}$. The cell mixture was centrifuged at $150 \times g$ for $5 \mathrm{~min}$ at $4^{\circ} \mathrm{C}$ to isolate BMEC. Total RNA was extracted using an RNA simple Total RNA Kit (DP419, Tian Gen, Beijing, China). The concentration of RNA was measured using a NanoDrop1000 spectrophotometer (Nanodrop/ThermoFisher Scientific, Waltham, MA). The optical density ratio at $260 / 280 \mathrm{~nm}\left(\mathrm{OD}_{260} / \mathrm{OD}_{280}\right)$ of RNA samples was $\geq 1.9$. The integrity of RNA was analyzed with the Agilent 2100 Bioanalyzer (Agilent Technologies, Santa Clara, CA) using the RNA 6000 Nano Kit (Agilent Technologies). Samples used for further analysis had an RNA integrity number $\geq 8.0$. The RNA was reversetranscribed to cDNA using the High-capacity cDNA Reverse Transcription Kits (4368814, Applied Biosystems, Carlsbad, CA). The reaction mixture contained 2 $\mu \mathrm{L}$ of $500 \mathrm{ng} / \mu \mathrm{L}$ RNA solution, $4 \mu \mathrm{L}$ of genomic DNA buffer, $4 \mu \mathrm{L}$ of FQ-RT Primer Mix, $2 \mu \mathrm{L}$ of RT Enzyme Mix, $4 \mu \mathrm{L}$ of Fast RT buffer, and $4 \mu \mathrm{L}$ of nuclease-free water (all reagents from Applied Biosystems). 
The cDNA was amplified by real-time PCR (7500, Applied Biosystems, Foster, CA) with Power SYBR Green PCR Master Mix and Power SYBR Green RTPCR Reagents Kit (4367659, Applied Biosystems). A $50-\mu \mathrm{L}$ reaction mixture containing $1,000 \mathrm{ng}$ of $\mathrm{cDNA}$ was used. The reaction cycle was as follows: polymerase activation at $95^{\circ} \mathrm{C}$ for $10 \mathrm{~min}$ followed by PCR of 40 cycles, where each cycle included a denaturation period at $95^{\circ} \mathrm{C}$ for $15 \mathrm{~s}$ and an annealing period at $60^{\circ} \mathrm{C}$ for $1 \mathrm{~min}$. The primer sequences of genes are listed in Supplementary Table S1 (https://doi.org/10.3168/jds2016-11823); GAPDH and $\beta$-actin were used as internal control genes. The expression of genes was calculated by using the $2^{-\Delta \Delta \mathrm{Ct}}$ method (Livak and Schmittgen, 2001).

The concentrations of $\alpha$-casein, $\beta$-casein, and $\kappa$-casein were detected using an ELISA kit from A\&B (DRE48745, Shanghai, China). The activity of arginase and NOS was determined with an arginase (DARG200, BioAssay Systems, Hayward, CA) and NOS kit (A014-2, Jianchen, Nanjing, China) following the manufacturers' protocols. In addition, activity of ornithine decarboxylase (ODC) was measured following the method reported by Ngo et al. (1987).

As shown in Table 1, activities of arginase and ODC decreased $(P=0.02)$ with addition of nor-NOHA to serum-free medium. However, the activity of NOS was not affected by nor-NOHA $(P=0.22)$. The relative gene expression of enzymes related to Arg metabolism is reported in Figure 1. Compared with control, the mRNA expression of both $A R G 1$ and $A R G 2$ in the Nor-NOHA treatment was lower $(P<0.01)$ but the difference among these treatments was not significant $(P$ $>0.05)$. The expression of $O D C$ in Nor-NOHA was also lower than that in control $(P<0.01)$. In addition, the expression of NOS3 in Nor-NOHA was similar to that in control $(P=0.16)$. The lower activity of arginase, lower expression of arginase subtypes, and the lack of effect on NOS activity and NOS3 expression with $1 \mathrm{mmol} / \mathrm{L}$ nor-NOHA in medium confirms data from studies in murine macrophages, human T-cells, and endothelial

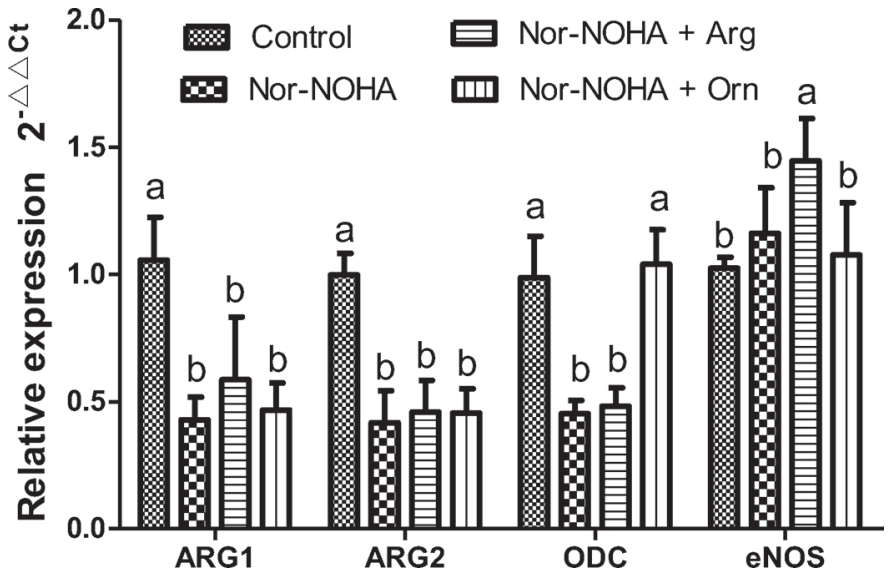

Figure 1. Effects of different treatments on gene expression (by delta cycle threshold method, $2^{-\Delta \Delta \mathrm{Ct}}$ ) of enzymes associated with Arg metabolism in bovine mammary epithelial cells. Control = Dulbecco's modified Eagle medium:Nutrient Mixture F-12 medium (DMEM/ F12); Nor-NOHA = DMEM/F12 $+1 \mathrm{mmol} / \mathrm{L} \quad N^{\omega}$-hydroxy-nor-Larginine (nor-NOHA); Nor-NOHA $+\mathrm{Arg}=\mathrm{DMEM} / \mathrm{F} 12+1 \mathrm{mmol} / \mathrm{L}$ nor-NOHA + $3.2 \mathrm{mmol} / \mathrm{L}$ Arg; Nor-NOHA+Orn $=$ DMEM $/ \mathrm{F} 12+$ $1 \mathrm{mmol} / \mathrm{L}$ nor-NOHA $+1 \mathrm{mmol} / \mathrm{L}$ Orn. Enzymes: ARG1= arginase 1; $\mathrm{ARG} 2=$ arginase 2; ODC $=$ ornithine decarboxylase; $\mathrm{eNOS}=$ endothelial nitric oxide synthase. Bars with different letters $(a, b)$ for a given enzyme represent significant differences $(P<0.05)$. Error bars $=$ SEM.

cells (Munder et al., 2006; Topal et al., 2006). Reid et al. (2007), using an injection of nor-NOHA in mice, detected lower activity and concentration of arginase without changes in activity of NOS. The activity of arginase and production of Orn decreased, resulting in a lower effect on ODC activity and $O D C$ expression.

Besides serving as a substrate, previous studies indicated that Arg elicits regulation on the activity of enzymes related to Arg metabolism through other mechanisms (Morris, 2004). Compared with the Nor-NOHA treatment, the addition of Arg (Nor-NOHA+Arg treatment) increased NOS activity in BMEC treated with nor-NOHA $(P<0.01)$ but had no effect on the activity of arginase $(P=0.56)$ or ODC $(P=0.08)$. Furthermore, the difference of the mRNA expression of $A R G 1(P=$ $0.11), A R G 2(P=0.51)$, and $O D C(P=0.66)$ between

Table 1. Effects of different treatments on activity of enzymes related to Arg metabolism in bovine mammary epithelial cells

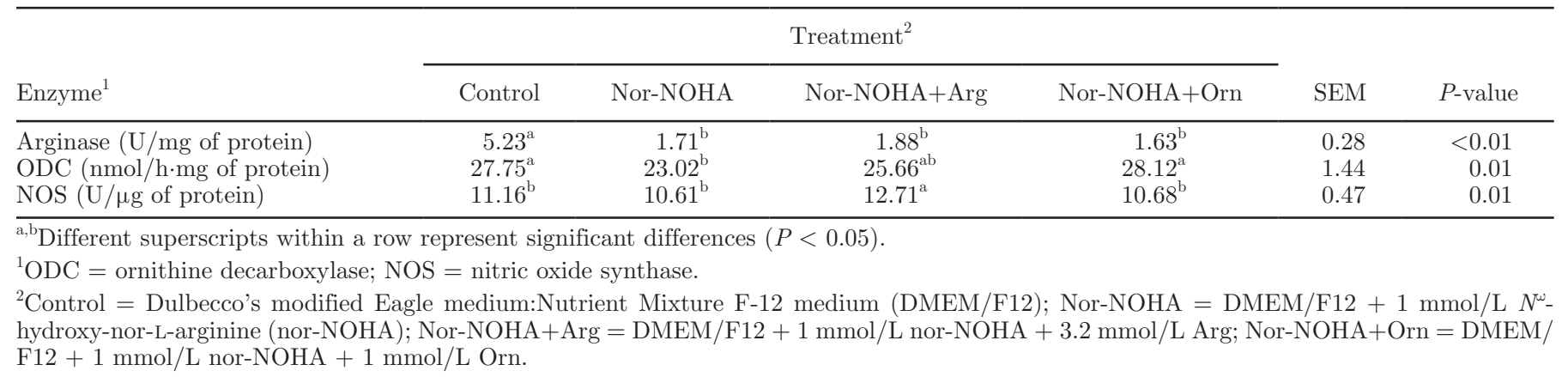


Nor-NOHA and Nor-NOHA+Arg was not significant. However, the expression of NOS3 in Nor-NOHA+Arg was higher than that in Nor-NOHA $(P=0.01)$. In a previous study, Gonzalez and Byus (1991) reported that the supplementation of Arg in diets of mice increased the activity of ODC, which partly contrasts the lack of effect of Arg in cultures with nor-NOHA, where no effect on the activity of arginase and ODC was detected. There was also no effect on mRNA expression of arginase and ODC. The responses we observed might have been due to the high efficiency of the inhibition of nor-NOHA on arginase. The increase in activity of NOS and the expression of NOS3 with Arg addition are in agreement with the findings of Morris et al. (2000) in humans supplemented with Arg. A link between availability of Arg and enzyme activity and gene expression is further underscored by a study in macrophages and astrocytes, where the low concentration of Arg in medium led to a reduction in NOS activity and NOS2 expression (El-Gayar et al., 2003; Manner et al., 2003).

In contrast to Arg, it has been reported that Orn (the product of arginase activity) has a negative effect on the activity of arginase (Hunter and Downs, 1945). In the current experiment, however, arginase activity $(P=0.78)$, NOS activity $(P=0.79)$, and expression of ARG1 $(P=0.70), A R G 2(P=0.55)$, and NOS3 $(P$ $=0.37$ ) were not significantly different in cultures with Nor-NOHA+Orn compared with Nor-NOHA alone. In contrast, supplementation of Orn to BMEC treated with nor-NOHA increased the expression of $O D C$ ( $P$ $<0.01)$ and activity of ODC $(P<0.01)$, which agrees with data from Gonzalez and Byus (1991), who demonstrated that activity and gene expression of ODC in mammary cancer cells was increased in rats supplemented with $2 \%$ Orn in the diet.

The optical density values detected in the MTT colorimetric assay demonstrated the proliferative ability of cells, where higher optical density values indicate greater cellular proliferation. In the present study, the proliferation of BMEC treated with Nor-NOHA and Nor-NOHA+Arg was significantly lower than that detected in the other 2 groups $(P<0.05)$ at 24,48 , and $72 \mathrm{~h}$ of culture (Figure 2), with no difference between Nor-NOHA and Nor-NOHA+Arg $(P>0.05)$. Several studies have reported that polyamines elicit positive effects on the proliferation of vastly different types of cells (Wright et al., 2014; Chen et al., 2015). Arginine is the rate-limiting enzyme of polyamine production, and some studies have reported that once the activity of arginase is inhibited, the proliferation of rat aortic smooth muscle cells and $\mathrm{T}$ lymphocytes is inhibited significantly (Wei et al., 2001; Rodriguez et al., 2003). Singh et al. (2000) reported that the proliferation of mammary cancer cells treated with NOHA was signifi-

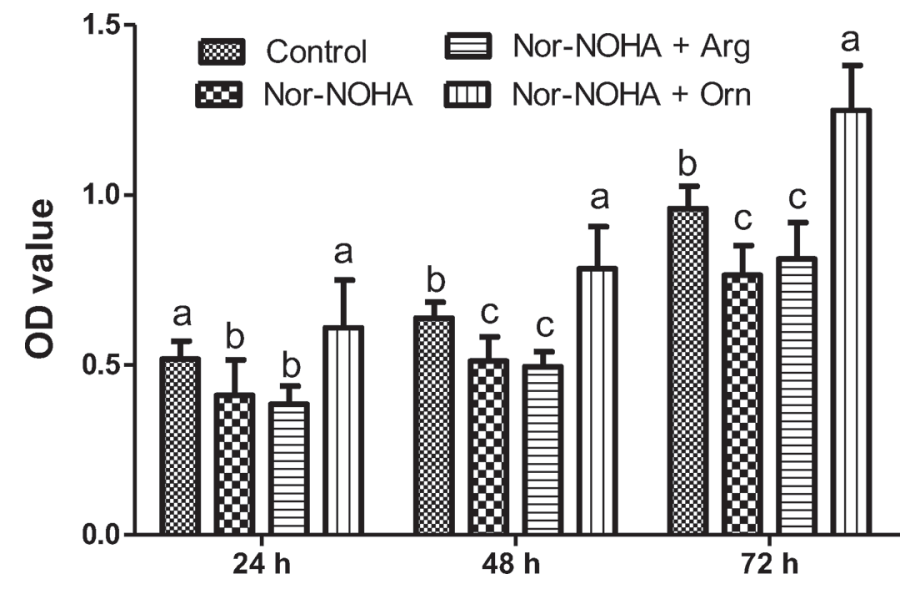

Figure 2. Effects of different treatments on the proliferation (measured by optical density, OD) of bovine mammary epithelial cells. Control $=$ Dulbecco's modified Eagle medium:Nutrient Mixture F-12 medium $(\mathrm{DMEM} / \mathrm{F} 12) ;$ Nor-NOHA $=\mathrm{DMEM} / \mathrm{F} 12+1 \mathrm{mmol} / \mathrm{L} N^{\omega}-$ hydroxy-nor-L-arginine (nor-NOHA); Nor-NOHA+Arg = DMEM/ $\mathrm{F} 12+1 \mathrm{mmol} / \mathrm{L}$ nor-NOHA $+3.2 \mathrm{mmol} / \mathrm{L} \mathrm{Arg}$; Nor-NOHA+Orn $=$ DMEM/F12 + $1 \mathrm{mmol} / \mathrm{L}$ nor-NOHA $+1 \mathrm{mmol} / \mathrm{L}$ Orn. Bars with different letters $(\mathrm{a}-\mathrm{c})$ within a timepoint represent significant differences $(P<0.05)$. Error bars $=$ SEM.

cantly lower than of untreated control cultures. These studies support the findings of the present study, where the addition of nor-NOHA decreased both arginase activity and the proliferation of BMEC. As a substrate of polyamine synthesis, Arg was also reported to activate proliferation of cells (Efron et al., 1991). In the studies of Kim et al. (2009) and Gil-Henn et al. (2013), the addition of Arg in medium increased the proliferation of ovine trophectoderm cells and breast cancer cells, respectively.

As a substrate of polyamine synthesis, Arg has been reported to activate proliferation of cells (Efron et al., 1991). The lack of difference in proliferation of BMEC between Nor-NOHA and Nor-NOHA+Arg in the present study (Figure 2) might have been due to the inhibition of arginase, leading to lower production of Orn. This is supported by the fact that addition of Orn to BMEC treated with nor-NOHA increased cellular proliferation even beyond that of control cultures. In this study, the proliferation of BMEC in Nor-NOHA+Orn increased and was similar to that of control $(P=0.06)$ at $24 \mathrm{~h}$ of culture. Over time, the proliferation of BMEC in Nor-NOHA + Orn continued to increase and was higher than that in control at $48 \mathrm{~h}(P=0.01)$ and $72 \mathrm{~h}$ $(P<0.01)$ of culture. These data are further supported by the study of Singh et al. (2000), which demonstrated that supplementing Orn to a medium with NOHA induced a normal rate of cellular proliferation.

In addition to accelerating proliferation of cells, the polyamine spermidine enhances synthesis of milk protein (Kong et al., 2014). Oka and Perry (1974b) 
Table 2. Effects of different treatments on casein concentration $(\mu \mathrm{g} / \mathrm{mg}$ of protein) in bovine mammary epithelial cells

\begin{tabular}{|c|c|c|c|c|c|c|}
\hline Item & \multicolumn{4}{|c|}{ Treatment $^{1}$} & SEM & $P$-value \\
\hline$\alpha_{\mathrm{S} 1}$-Casein & $440.39^{\mathrm{b}}$ & $398.08^{c}$ & $418.02^{\mathrm{bc}}$ & $506.68^{\mathrm{a}}$ & 11.52 & $<0.01$ \\
\hline$\beta$-Casein & $303.16^{\mathrm{b}}$ & $238.75^{\mathrm{c}}$ & $237.06^{\mathrm{c}}$ & $322.00^{\mathrm{a}}$ & 7.10 & $<0.01$ \\
\hline$\kappa$-Casein & $102.17^{\mathrm{a}}$ & $89.41^{\mathrm{b}}$ & $88.26^{\mathrm{b}}$ & $101.29^{\mathrm{a}}$ & 4.12 & 0.02 \\
\hline
\end{tabular}

${ }^{a-c}$ Different superscripts within a row represent significant differences $(P<0.05)$.

${ }^{1}$ Control $=$ Dulbecco's modified Eagle medium:Nutrient Mixture F-12 medium (DMEM/F12); Nor-NOHA $=$ DMEM/F12 +1 mmol/L $N^{\omega}-$ hydroxy-nor-L-arginine (nor-NOHA); Nor-NOHA+Arg = DMEM/F12 + 1 mmol/L nor-NOHA + 3.2 mmol/L Arg; Nor-NOHA+Orn = DMEM/ $\mathrm{F} 12+1 \mathrm{mmol} / \mathrm{L}$ nor-NOHA + $1 \mathrm{mmol} / \mathrm{L}$ Orn

reported that the production of spermidine and milk protein decreased during inhibition of spermidine synthase in bovine mammary gland cultures in vitro. It was also reported that putrescine can induce protein synthesis in body tissues (Pegg, 1988). Thus, as the rate-limiting enzymes which can catalyze Arg to both spermidine and putrescine in the mammary gland, while the activity of arginase is reduced, the rate of milk protein synthesis is expected to decrease.

As shown in Table 2, the addition of nor-NOHA decreased activity of arginase and led to a trend toward decreasing the synthesis of $\alpha_{\mathrm{S}_{1}}$-casein, $\alpha_{\mathrm{S} 2}$-casein, $\beta$-casein, and $\kappa$-casein in BMEC compared with control $(P<0.01)$. Furthermore, the mRNA expression of CSN1S1, CSN1S2, CSN2, and CSN3 also decreased with the supplementation of nor-NOHA in medium compared with control $(P<0.01)$. Folley and Greenbaum (1947) and Yip and Knox (1972) also reported

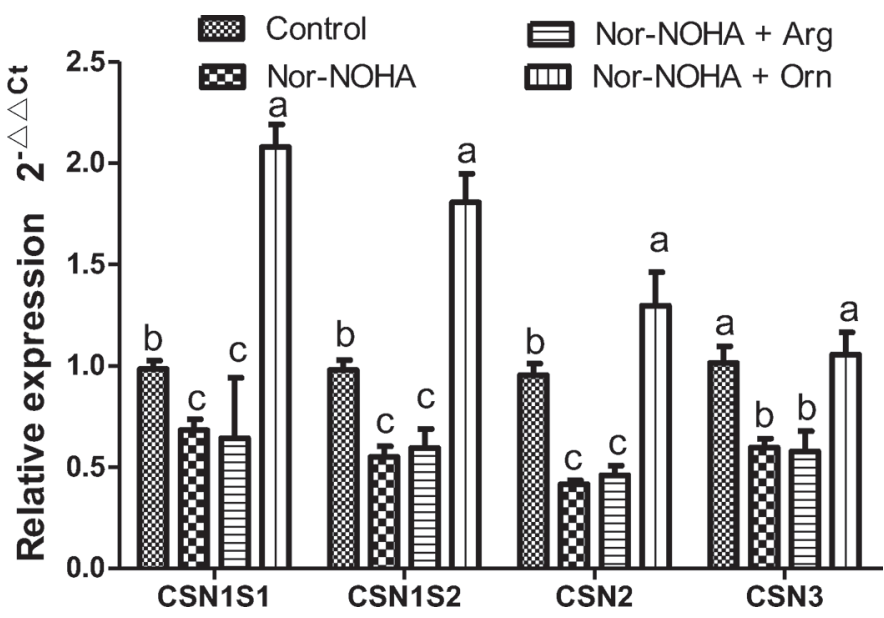

Figure 3. Effects of different treatments on gene expression (by delta cycle threshold method, $2^{-\Delta \Delta \mathrm{Ct}}$ ) of casein in bovine mammary epithelial cells. Control = Dulbecco's modified Eagle medium:Nutrient Mixture F-12 medium (DMEM/F12); Nor-NOHA = DMEM/F12 + $1 \mathrm{mmol} / \mathrm{L} N^{\omega}$-hydroxy-nor-L-arginine (nor-NOHA); Nor-NOHA+Arg $=\mathrm{DMEM} / \mathrm{F} 12+1 \mathrm{mmol} / \mathrm{L}$ nor-NOHA $+3.2 \mathrm{mmol} / \mathrm{L}$ Arg; Nor$\mathrm{NOHA}+\mathrm{Orn}=\mathrm{DMEM} / \mathrm{F} 12+1 \mathrm{mmol} / \mathrm{L}$ nor-NOHA $+1 \mathrm{mmol} / \mathrm{L}$ Orn. Genes: CSN1S1 $=\alpha_{\mathrm{S}_{1}} \mathrm{CN} ; C S N 1 S 2=\alpha_{\mathrm{S}_{2}} \mathrm{CN} ; C S N 2=\beta-\mathrm{CN}$; CSN3 $=\kappa-C N$. Bars with different letters $(\mathrm{a}-\mathrm{c})$ within a casein gene represent significant differences $(P<0.05)$. Error bars $=$ SEM. that the synthesis of milk protein was correlated with the activity of arginase in mammary gland. Oka and Perry (1974a) reported that the rate of milk protein synthesis increased when arginase activity in bovine mammary gland increased.

As shown in our previous studies (Wang et al., 2014; Wu et al., 2016), Arg plays an important role in increasing casein synthesis in BMEC. However, in the present study, addition of Arg into the medium with nor-NOHA had no effects on the synthesis and concentrations of $\alpha_{S_{1}}$-casein $(P=0.10), \alpha_{S^{2}}$-casein $(P=0.46), \beta$-casein $(P=0.81)$, or $\kappa$-casein $(P=0.78)$ compared with NorNOHA only. The mRNA expression of CSN1S1 $(P=$ $0.63), C S N 1 S 2(P=0.34), C S N 2(P=0.33)$, and $C S N 3$ $(P=0.68)$ was also not affected (Figure 3$)$. This may be due to nor-NOHA inhibiting the activity of arginase; thus, preventing the transformation of Arg to Orn and polyamines even when the substrate (Arg) concentration increased, and inhibiting the synthesis of casein.

In contrast, the addition of Orn into the medium with nor-NOHA increased the protein concentration and expression of different casein subtypes compared with that treated with only nor-NOHA (Figure $3 ; P<0.01$ ). A possible reason might be that Orn is the product of Arg in the Arg-arginase-Orn pathway, which should not be affected by arginase activity, thus, it increased the concentration of casein protein.

In summary, inhibition of the Arg-Orn pathway with nor-NOHA reduced the synthesis of casein and mammary cell proliferation, and the addition of Orn (the product of the Arg-Orn pathway) helped in the recovery of normal casein synthesis and rate of cellular proliferation. However, Arg (the substrate of the Arg-Orn pathway) had no effect on casein synthesis or cellular proliferation. Our results indicate that the Arg-Orn pathway is a key regulator of the synthesis of casein in BMEC.

\section{ACKNOWLEDGMENTS}

This work was supported by a National Basic Research (973) Program of China (2011CB100803), Bei- 
jing; a key project from Yangsheng Mensheng Group (2016A20031), Nanjing and Priority Academic Program Development of Jiangsu Higher Education Institutions (PAPD), Nanjing, China.

\section{REFERENCES}

Bionaz, M., B. J. Thering, and J. J. Loor. 2012. Fine metabolic regulation in ruminants via nutrient-gene interactions: Saturated longchain fatty acids increase expression of genes involved in lipid metabolism and immune response partly through PPAR- $\alpha$ activation. Br. J. Nutr. 107:179-191.

Chen, J. L., X. Bi, H. Zhang, F. Wang, Y. Wang, and Z. Guo. 2015. Putrescine promotes human marrow mesenchymal stem cells to differentiate along osteogenic pathway. Zhongguo Shi Yan Xue Ye Xue Za Zhi 23:809-813.

Chen, L., Z. Li, M. Wang, and H. Wang. 2013. Preliminary report of arginine on synthesis and gene expression of casein in bovine mammary epithelial cell. Int. Res. J. Agric. Sci. Soil Sci. 3:17-23.

Custot, J., C. Moali, M. Brollo, J. Boucher, M. Delaforge, D. Mansuy, J. Tenu, and J. Zimmermann. 1997. The new $\alpha$-amino acid Nw-hydroxy-nor-L-arginine: A high-affinity inhibitor of arginase well adapted to bind to its manganese cluster. J. Am. Chem. Soc. 119:4086-4087.

Doepel, L., and H. Lapierre. 2011. Deletion of arginine from an abomasal infusion of amino acids does not decrease milk protein yield in Holstein cows. J. Dairy Sci. 94:864-873.

Efron, D. T., S. Kirk, M. Regan, H. Wasserkrug, and A. Barbul. 1991. Nitric oxide generation from l-arginine is required for optimal human peripheral blood lymphocyte DNA synthesis. Surgery 110:327-334

El-Gayar, S., H. Thüring-Nahler, J. Pfeilschifter, M. Röllinghoff, and C. Bogdan. 2003. Translational control of inducible nitric oxide synthase by IL-13 and arginine availability in inflammatory macrophages. J. Immunol. 171:4561-4568.

Folley, S. J., and A. Greenbaum. 1947. Changes in the arginase and alkaline phosphatase contents of the mammary gland and liver of the rat during pregnancy, lactation and mammary involution. Biochem. J. 41:261.

Gil-Henn, H., A. Patsialou, Y. Wang, M. S. Warren, J. S. Condeelis, and A. J. Koleske. 2013. Arg/abl2 promotes invasion and attenuates proliferation of breast cancer in vivo. Oncogene 32:2622-2630.

Gonzalez, G. G., and C. Byus. 1991. Effect of dietary arginine restriction upon ornithine and polyamine metabolism during two-stage epidermal carcinogenesis in the mouse. Cancer Res. 51:2932-2939.

Hunter, A., and C. E. Downs. 1945. The inhibition of arginase by amino acids. J. Biol. Chem. 157:427-446.

Iniesta, V., L. C. Gómez-Nieto, and I. Corraliza. 2001. The inhibition of arginase by nw-hydroxy-L-arginine controls the growth of Leishmania inside macrophages. J. Exp. Med. 193:777-784.

Kim, J., T. E. Spencer, R. C. Burghardt, G. Wu, G. A. Johnson, and F. W. Bazer. 2009. Arginine stimulates proliferation of ovine trophectoderm cells through FRAP1-RPS6K-RPS6 signaling cascade and synthesis of nitric oxide and polyamines. Biol. Reprod. 81(Suppl. 1):488. (Abstr.)

Kong, X., X. Wang, Y. Yin, X. Li, H. Gao, F. W. Bazer, and G. Wu. 2014. Putrescine stimulates the mtor signaling pathway and protein synthesis in porcine trophectoderm cells. Biol. Reprod. 91:106.

Li, H., C. J. Meininger, J. R. Hawker, T. E. Haynes, D. Kepka-Lenhart, S. K. Mistry, S. M. Morris, and G. Wu. 2001. Regulatory role of arginase I and II in nitric oxide, polyamine, and proline syntheses in endothelial cells. Am. J. Physiol. Endocrinol. Metab. 280:E75-E82.

Livak, K. J., and T. D. Schmittgen. 2001. Analysis of relative gene expression data using real-time quantitative PCR and the $2-\Delta \Delta \mathrm{CT}$ method. Methods 25:402-408.

Mabjeesh, S. J., C. Kyle, J. MacRae, M. Hanigan, and B. Bequette. 2002. Vascular sources of amino acids for milk protein synthesis in goats at two stages of lactation. J. Dairy Sci. 85:919-929.
Manner, C. K., B. Nicholson, and C. L. MacLeod. 2003. Cat2 arginine transporter deficiency significantly reduces INOS-mediated no production in astrocytes. J. Neurochem. 85:476-482.

Morris, C. R., F. A. Kuypers, S. Larkin, N. Sweeters, J. Simon, E. P. Vichinsky, and L. A. Styles. 2000. Arginine therapy: A novel strategy to induce nitric oxide production in sickle cell disease. Br. J. Haematol. 111:498-500.

Morris, S. M. 2004. Enzymes of arginine metabolism. J. Nutr. 134:2743S-2747S

Munder, M., H. Schneider, C. Luckner, T. Giese, C.-D. Langhans, J. M. Fuentes, P. Kropf. I. Mueller, A. Kolb, and M. Modolell. 2006. Suppression of T-cell functions by human granulocyte arginase. Blood 108:1627-1634.

Ngo, T. T., K. L. Brillhart, R. H. Davis, R. C. Wong, J. H. Bovaird, J. J. Digangi, J. L. Ristow, J. L. Marsh, A. P. Phan, and H. M. Lenhoff. 1987. Spectrophotometric assay for ornithine decarboxylase. Anal. Biochem. 160:290-293.

O'Quinn, P. R., D. Knabe, and G. Wu. 2002. Arginine catabolism in lactating porcine mammary tissue. J. Anim. Sci. 80:467-474.

Oka, T., and J. W. Perry. 1974a. Arginase affects lactogenesis through its influence on the biosynthesis of spermidine. Nature 250:660661.

Oka, T., and J. W. Perry. 1974b. Spermidine as a possible mediator of glucocorticoid effect on milk protein synthesis in mouse mammary epithelium in vitro. J. Biol. Chem. 249:7647-7652.

Pegg, A. E. 1988. Polyamine metabolism and its importance in neoplastic growth and as a target for chemotherapy. Cancer Res. 48:759-774.

Reid, K. M., A. Tsung, T. Kaizu, G. Jeyabalan, A. Ikeda, L. Shao, G. Wu, N. Murase, and D. A. Geller. 2007. Liver i/r injury is improved by the arginase inhibitor, nw-hydroxy-nor-l-arginine (nor-noha). Am. J. Physiol. Gastrointest. Liver Physiol. 292:G512-G517.

Rodriguez, P. C., A. H. Zea, J. DeSalvo, K. S. Culotta, J. Zabaleta, D. G. Quiceno, J. B. Ochoa, and A. C. Ochoa. 2003. L-Arginine consumption by macrophages modulates the expression of $\mathrm{cd} 3 \zeta$ chain in t lymphocytes. J. Immunol. 171:1232-1239.

Singh, R., S. Pervin, A. Karimi, S. Cederbaum, and G. Chaudhuri. 2000. Arginase activity in human breast cancer cell lines: $\mathrm{N} \omega-$ hydroxy-L-arginine selectively inhibits cell proliferation and induces apoptosis in mda-mb-468 cells. Cancer Res. 60:3305-3312.

Topal, G., A. Brunet, L. Walch, J.-L. Boucher, and M. David-Dufilho. 2006. Mitochondrial arginase ii modulates nitric-oxide synthesis through nonfreely exchangeable L-arginine pools in human endothelial cells. J. Pharmacol. Exp. Ther. 318:1368-1374.

Wang, M., B. Xu, H. Wang, D. Bu, J. Wang, and J.-J. Loor. 2014. Effects of arginine concentration on the in vitro expression of casein and mtor pathway related genes in mammary epithelial cells from dairy cattle. PLoS One 9:e95985.

Wei, L. H., G. Wu, S. M. Morris, and L. J. Ignarro. 2001. Elevated arginase I expression in rat aortic smooth muscle cells increases cell proliferation. Proc. Natl. Acad. Sci. USA 98:9260-9264.

Wright, D. B., H. Meurs, and B. G. Dekkers. 2014. Integrins: Therapeutic targets in airway hyperresponsiveness and remodelling? Trends Pharmacol. Sci. 35:567-574.

Wu, G., F. W. Bazer, T. A. Davis, S. W. Kim, P. Li, J. M. Rhoads, M. C. Satterfield, S. B. Smith, T. E. Spencer, and Y. Yin. 2009. Arginine metabolism and nutrition in growth, health and disease. Amino Acids 37:153-168.

Wu, G., N. E. Flynn, D. A. Knabe, and L. A. Jaeger. 2000. A cortisol surge mediates the enhanced polyamine synthesis in porcine enterocytes during weaning. Am. J. Physiol. Regul. Integr. Comp. Physiol. 279:R554-R559.

Wu, T., C. Wang, L. Ding, Y. Shen, H. Cui, M. Wang, and H. Wang. 2016. Arginine relieves the inflammatory response and enhances the casein expression in bovine mammary epithelial cells induced by lipopolysaccharide. Mediators Inflamm. 2016:9618795.

Yip, M. C., and W. E. Knox. 1972. Function of arginase in lactating mammary gland. Biochem. J. 127:893-899. 